Mitja Skubic

Universidad de Ljubljana

\title{
EL LINGÜISTA ESLOVENO BARTOLOMÉ KOPITAR Y EL IBERORROMANCE
}

En esta misma revista, véanse los volúmenes X y XII, ya hemos presentado testigos del conocimiento e interés en el pasado esloveno de los acontecimientos de la vida política de España por parte de los periodistas eslovenos en el primer volumen citado y de la literatura española por parte del poeta esloveno Francè Prešeren en el segundo. En la presente contribución querríamos añadir una breve nota no tanto sobre el conocimiento práctico sino sobre el interés lingüístico por la lengua española por parte de un importante lingüista esloveno de las primeras décadas del siglo XIX, Bartolomé (Jernej en esloveno) Kopitar.

Kopitar (Repnje, en el distrito de Ljubljana, 1780 - Viena, 1844) fue scriptor en la Biblioteca de la corte imperial de Viena y censor de las publicaciones en lenguas eslavas meridionales, en griego y en rumano editadas en el imperio de los Habsburgo. Con sus trabajos sobre las correspondencias entre las lenguas balcánicas de distinto origen genético (el rumano, el búlgaro, el albanés) es considerado precursor de la corriente lingüística que, sólo unos cien años más tarde, el lingüista danés Christian Sandfeld denominó lingui-stique balkanique. Kopitar apoyó su convicción de las relaciones entre estos tres idiomas en la existencia y la posición del artículo determinativo y del pronombre posesivo que se colocan detrás del substantivo, en el escaso empleo del infinitivo y, como consecuencia, del de la construcción del futuro romance que en los idiomas romances, excepto en rumano, se forma mediante el auxiliar haber + infinitivo, mientras que las lenguas balcánicas recurren al verbo modal quaerere y, sobre todo, recurren a la subordinación. Por el uso restringido del infinitivo, que el uso popular aborrece, escasean las subordinadas implícitas, características de las lenguas románicas, substituidas por las explícitas, continuando así, por ejemplo, el non possum ut faciam de la latinidad oriental.

Kopitar es el autor de la primera gramática de valor científico de la lengua eslovena, editada en Ljubljana: Grammatik der slavischen Sprache in Krain, Kärnten und Steyermark, Laibach 1808. Fue eslavista e investigador de las lenguas eslavas, pero tenía también un buen conocimiento teórico y práctico del francés y del italiano, por lo que atestigua su correspondencia en estas dos lenguas románicas. En su autobiografía Kopitar afirma que aprendió el italiano en la casa del noble carniolo de procedencia italiana de las cercanías de Bergamo, Sigismund Zois, industrial, poeta y, sobre todo, mecenas de los artistas eslovenos, donde Kopitar desempeñó el cargo de maestro de un nieto de Zois. Es sabido también que en la misma casa enseñó el esloveno a una joven noble y para ella compuso en francés una gramática de uso de la lengua eslovena. En cuanto al italiano, en 1838 uno de los correspondientes de Kopitar le escribe en lengua italiana sabiendo che la conosce al pari di qualunque italiano. De su conocimiento del español no hay vestigios en su correspondencia y está claro que, a parte de los dos idiomas romances ya mencionados, era el rumano, por la situación lingüística en la península balcánica, él que más le atraía. 
No obstante, su reseña de un diccionario de rumano, latín y húngaro, Dictionariu Rumanesc, Latinesc şi Unguresc, Clus 1822-23, y de Lesicon Romanescu-Latinescu-Ungurescu-Nemțescu, Budae, 1825, publicada en Jahrbücher der Literatur, t. 46, Wien 1829, págs. 227-273, bajo el título de Albanische, walachische u. bulgarische Sprache, demuestra que la situación lingüística de la Península Ibérica no le fue desconocida. La reseña brindó a Kopitar la oportunidad de repetir su convicción sobre la utilidad de la grafía fonética que según él era el ideal para los idiomas que apenas estaban buscando una norma de la lengua escrita, como era el caso justamente del valaco, es decir, del rumano. Éste idioma, como se sabe, abandonó por completo la grafía de los caracteres cirílicos (sistema que recurre a la grafía fonética como por ejemplo el serbio) sólo a mediados del siglo XIX. Como prueba de la superioridad de la grafía fonética Kopitar presenta el italiano y el español, porque, dice, escriben respectivamente buono y puerta y no bono y porta como exigiría un rígido arraigo a la etimología latina.

Kopitar es partidario de la grafía fonética, no etimológica, y aduce, en apoyo de sus ideas, a Quintiliano: Ego (nisi quod consuetudo obtinuerit) sic scribendum quidque judico, quomodo sonat; hic enim est usus literarum, ut custodiant voces, et velum depositum reddant, legentibus. Si esto es el ideal para los idiomas con una tradición fija, como eran en su tiempo el italiano y el español, tanto más era recomendable para el rumano, donde no había consenso. En una nota en la página 241 Kopitar se muestra muy resuelto ( Der Spanier schreibt, weil er so spricht») y cita unas cien palabras españolas con las respectivas fuentes latinas, entre las cuales se encuentran substantivos como nombres de persona Inés de Agnes, Andrés de Andreas, Gerónimo de Hieronymus, nombres de situación o actividades humanas hombre de homo, muger de mulier, hermano de germanus, abogado de advocatus, obispo de episcopus, emperador de imperator, súbdito de subditus, apelativos tierra de terra, oro de aurum, fuego de focus, hiel de fel, hueso de os, queso de caseus, animales abispa de vespa, cisne de cygnus, lobo de lupus, adjetivos como igual de aequalis, ciego de caecus, pobre de pauper, verbos como llamar de clamare, llorar de plorare, manjar de manducare, leer de legere, caer de cadere, numerales como ocho de octo, cinco de quinque, doce de duodecim, adverbios como hoy de hodie, mucho de multus y termina la lista con u.s.w., u.s.w., declarando así que la lista podría continuar. A dicha lista le fueron añadidas también unas palabras lusitanas: doutor, doutrina de doctor, doctrina, mau de mal, grão de grano, nobre de noble, chamar de clamare, chantar, chão, cheio, chorar, chover, chumbo de plantare, plano, pleno, plorare, pluere, plumbum, u.s.w., u.s.w.

Bartolomé Kopitar pone de relieve algunas particularidades en la grafía del español y del portugués, respectivamente, mostrando un buen conocimiento de la norma de la lengua escrita de las dos lenguas románicas. Pero no sólo de la escritura. Contestando el principio del recurso a la rígida grafía etimológica, muestra, sin desearlo, su competencia en evaluar importantes fenómenos lingüísticos (fonéticos) ocurridos al latín en el territorio iberorromance: sonorización de las oclusivas sordas en posición intervocálica, palatalización de la líquida $l$ en el grupo $p l$ y la subsiguiente palatalización del grupo, palatalización de los grupos consonánticos $k t, l t$, sibilantización de las velares delante de la palatal breve $i+$ vocal, diptongación de las vocales acentuadas $e, o$, simplificación del diptongo AU, aféresis de la vocal átona inicial, abertura de las vocales breves $i, u$ hacia $e, o$, aspiración de la labiodental sorda en castellano, reducción de las sílabas intertónicas con la caída de las vocales débiles, caída de las vocales finales átonas. Ya es bastante para decir, no que Kopitar fuese un hispanista, pero sí que conocía el sistema por lo menos fonético y gráfico del español y del portugués y, por lo tanto, estaba calificado para estimar 
la importancia de los fenómenos lingüísticos del iberorromance para el problema que en aquel entonces más le interesaba: el de sugerir la norma para el rumano de su tiempo que estaba por abandonar la escritura explícitamente fonética con los caracteres cirílicos, corriendo con esto el peligro de poner en cuestión la norma estrictamente fiel al uso del habla cotidiana. La escritura, es la convicción de Kopitar, tiene como obligación primaria la de manifestar clara y fielmente la pronunciación.

\section{JERNEJ KOPITAR IN IBEROROMANŠČINA}

Jernej Kopitar piše v svoji avtobiografiji, da se je italijanščine naučil v Zoisovi rodbini, francoščina pa mu je bila domača že prej, če je prav pri Zoisu poučeval slovenščino neko mlado plemkinjo in za ta pouk v francoščini sestavil elementaren učbenik. Dopisovanje s francoskimi in italijanskimi korespondenti dokazuje njegovo usposobljenost $\mathrm{v}$ teh dveh romanskih jezikih. Njihovi odgovori so večkrat polni hvale tudi o jeziku. Za vsaj pasivno poznavanje romunščine je dokaz ena od njegovih zadolžitev v Dvorni knjižnici na Dunaju: bil je za habsburško cesarstvo cenzor tudi za tiske v romunščini. Razen tega tudi dejstvo, da je pravzaprav pionir nove veje v jezikoslovju, tiste, ki jo je šele sto let pozneje danski jezikoslovec Christian Sandfeld poimenoval linguistique balkanique, se pravi ugotovitve o skupnih črtah med tremi balkanskimi, sicer genetsko nesorodnimi jeziki, romunščino, bolgarščino in albanščino.

Naš prispevek želi povedati, da je imel Kopitar tudi solidno znanje v kastiljščini in portugalščini. Ko je ocenjeval dve deli, ki sta se sicer ukvarjali z navedenimi balkanskimi jeziki, je za zgled pisne norme ob italijanščini postavil ravno ta dva iberoromanska jezika: vzor za pisno norma imata v govoru, tako dokazuje Kopitar $\mathrm{z}$ obilnimi zgledi iz kastiljščine in luzitanščine; to pa je bilo zanj resnično vodilo, česar naj bi se oprijela tudi pisna norma v romunščini. Ta je prav v njegovi dobi opuščala docela fonetično pisavo $v$ cirilici in se počasi oprijemala latinice. 